\title{
BMJ Open SARS-CoV-2 seroprevalence in students and teachers: a longitudinal study from May to October 2020 in German secondary schools
}

\author{
Carolin Kirsten, ${ }^{1}$ Manja Unrath, ${ }^{1}$ Christian Lück, ${ }^{2}$ Alexander H Dalpke, ${ }^{2}$ \\ Reinhard Berner, ${ }^{1}$ Jakob Armann (i) ${ }^{1}$
}

To cite: Kirsten C, Unrath M, Lück C, et al. SARS-CoV-2 seroprevalence in students and teachers: a longitudinal study from May to October 2020 in German secondary schools. BMJ Open 2021;11:e049876. doi:10.1136/ bmjopen-2021-049876

- Prepublication history and supplemental material for this paper is available online. To view these files, please visit the journal online (http://dx.doi. org/10.1136/bmjopen-2021049876).

Received 05 February 2021 Accepted 27 May 2021
Check for updates

(c) Author(s) (or their employer(s)) 2021. Re-use permitted under CC BY-NC. No commercial re-use. See rights and permissions. Published by BMJ.

${ }^{1}$ Department of Pediatrics, Technische Universität Dresden, Dresden, Germany ${ }^{2}$ Institute for Virology and Institute for Medical Microbiology and Hygiene, Technische Universität Dresden, Dresden, Germany

Correspondence to Dr Jakob Armann; jakob.armann@uniklinikumdresden.de

\section{ABSTRACT}

Objective To quantify the number of SARS-CoV-2 infections in secondary schools after their reopening in May 2020.

Design Repeated SARS-CoV-2 seroprevalence study after the reopening of schools and 4 months later.

Setting Secondary school in Dresden, Germany.

Participants 1538 students grades 8-12 and 507 teachers from 13 schools.

Interventions Serial blood sampling and SARS-CoV-2 IgG antibody assessment.

\section{Primary and secondary outcome}

measure Seroprevalence of SARS-CoV-2 antibodies in study population. Number of undetected cases.

Results 1538 students and 507 teachers were initially enrolled, and 1334 students and 445 teachers completed both study visits. The seroprevalence for SARS-CoV-2 antibodies was $0.6 \%$ in May/June and the same in September/October. Even in schools with reported COVID-19 cases before the lockdown of 13 March, no clusters could be identified. of 12 persons with positive serology five had a known history of confirmed COVID-19; 23 out of 24 participants with a household history of COVID-91 were seronegative.

Conclusions Schools do not play a crucial role in driving the SARS-CoV-2 pandemic in a low-prevalence setting. Transmission in families occurs very infrequently, and the number of unreported cases is low in this age group. These observations do not support school closures as a strategy fighting the pandemic in a low-prevalence setting. Trial registration number DRKS00022455.

\section{INTRODUCTION}

Since the identification of the SARS-CoV-2 as the cause of COVID-19 in December 2019, the virus spread rapidly around the world, leading to the declaration of a pandemic by the WHO on 12 March 2020. By 18 March 2020, 126 countries-including Germanyhad implemented school closures as part of their pandemic control measures, with the number of countries peaking at 194 on 10 April 2020 and more than $90 \%$ of the world's
Strengths and limitations of this study

- Seroprevalence can detect mildly or asymptomatic SARS-CoV-2 infections.

- Longitudinal study designs track individuals over time.

- Older students with multiple social contacts are a relevant target for pandemic control measures.

Loss to follow-up.

student population being affected at this point. $^{23}$

These actions were mainly based on the assumption that children play a similar role in transmitting SARS-CoV-2 as they do in transmitting influenza during outbreaks, for which evidence exists that school closures reduce the peak of the outbreak. ${ }^{4}$ However, there is reason to believe that children play a less significant role in SARS-CoV-2 transmission compared with influenza, making control measures focused on this age group less effective: most countries-including Germany-report a much lower proportion of cases in children compared with their population size ${ }^{5-7}$ and a recent review on population-based seroprevalence studies found no evidence of over-representation of schoolchildren. ${ }^{8}$ In addition, several tracing studies in schools in different countries could only identify minimal spread of SARS-CoV-2 in educational settings. ${ }^{9-11}$

However, currently available data are insufficient to rule out that children are as likely as adults to be infected by and to transmit SARS-CoV-2 but simply show little to no symptoms of the disease.

We therefore aimed to quantify the proportion of adolescent schoolchildren and teachers in Saxony, one of the eastern federal states of Germany, that already have developed antibodies against SARS-CoV-2. Until 
autumn 2020, in Saxony, the infection rates were comparatively low with 245 laboratory-confirmed SARS-CoV-2 infections per 100000 inhabitants as of 13 October 2020.

\section{METHODS}

\section{Study design}

After the reopening of the schools in Saxony on 18 May 2020 students grades $8-11$ and their teachers in 13 secondary schools in eastern Saxony were invited to participate in the SchoolCoviDD19 study. Schools were chosen by the state office for schools and education without involvement of the study team out of the 537 secondary schools in Saxony. Only the selected schools were contacted; none of them declined participation. All eligible students and teachers were invited to participate at each school. Participation rates varied from $12 \%$ to $50 \%$ per school.

After teachers, students and their legal guardians provided informed consent, $5 \mathrm{~mL}$ of peripheral venous blood was collected from each individual during visits at each participating school between 25 May and 30 June 2020. In addition, participants were asked to complete a questionnaire on age, household size, previously diagnosed SARS-CoV-2 infections in themselves or their household contacts, comorbidities and regular medication. Students were also asked about regular social contacts outside their household or classroom.

A second visit and repeat blood sampling of the same participants took place between 15 September and 13 October 2020. Between the two study visits, schools in Saxony remained open with the regular summer break from 20 July to 28 August 2020.

\section{Approval}

The SchoolCoviDD19 study was approved by the ethics committee of the Technische Universität Dresden (BOEK-156042020) and was registered on 23 July 2020 and assigned the clinical trial registration number DRKS00022455.

\section{Laboratory analysis}

We assessed SARS-CoV-2 IgG antibodies in all samples using a commercially available chemiluminescence immunoassay technology for the quantitative determination of anti-S1 and anti-S2 specific IgG antibodies to SARS-CoV-2 (DiaSorin LIAISON SARS-CoV-2 S1/S2 IgG assay-sensitivity, 97.6\%; specificity, 99.3\%). Antibody levels $>15 \mathrm{AU} /$ $\mathrm{mL}$ were considered positive, and levels between 12 and $15 \mathrm{AU} / \mathrm{mL}$ were considered equivocal.

All samples with a positive or equivocal LIAISON test result, as well as all samples from participants with a reported personal or household history of a SARS-CoV-2 infection, were retested with two additional serological tests: these were a chemiluminescent microparticle immunoassay intended for the qualitative detection of IgG antibodies to the nucleocapsid protein of SARS-CoV-2 (Abbott Diagnostics ARCHITECT SARS-CoV-2 IgG-specificity,
$99.6 \%$; sensitivity, $97.9 \%$ ) (an index $(\mathrm{S} / \mathrm{C})$ of $<1.4$ was considered negative, whereas one $\geq 1.4$ was considered positive) and an ELISA detecting IgG against the S1 domain of the SARS-CoV-2 spike protein (Euroimmun Anti-SARS-CoV-2 ELISA-specificity, 98.3\%; sensitivity, $96.9 \%$ ) (a ratio of $<0.8$ was considered negative, $0.8-1.1$ equivocal and $>1.1$ positive).

Participants whose positive or equivocal LIAISON test result could be confirmed by a positive test result in at least one additional serological test were considered having antibodies against SARS-CoV-2.

\section{Statistical analysis}

Analyses were performed using IBM SPSS V.25.0 and Microsoft Excel 2010. Results for continuous variables are presented as medians with IQR and categorical variables as numbers with percentages, unless stated otherwise.

A sample size calculation was performed based on an expected seroprevalence of $1 \%$ with $5 \%$ precision and a 95\% confidence level, which yielded a minimum sample size of 500 participants, which we exceeded at both timepoints.

\section{Patient and public involvement}

The public was not involved in the design, recruitment and conduct of the study. Participants are able to receive their personal serological test result on request.

\section{RESULTS}

A total of 1538 students and 507 teachers from 13 different schools participated in the first visit of the study; 1334 students and 445 teachers completed the second visit. Demographic data are shown in table 1.

Seroprevalence of SARS-CoV-2 antibodies was $0.6 \%$ $(12 / 2045)$ at the initial visit (May/June) with twelve participants-eleven students and one teacher-having detectable antibodies against SARS-CoV-2 in at least two different assays and thus being considered seropositive. At the follow-up visit (September/October), seroprevalence was $0.7 \%(12 / 1779)$ with still eleven seropositive students and one teacher. Remarkably, one participant who tested positive in two assays in May tested positive in only one assay in October and was therefore no longer considered seropositive per study definition, while one participant with equivocal results initially did test positive in two serological tests 3 months later. The remaining 11 seropositive participants had no changes in their test results. Using more liberal ( $\geq 1$ test positive) or more conservative (three tests positive) definitions for seropositivity does not change the persistent low seroprevalence in the study population (online supplemental table 1). In seven out of 13 schools, seropositive participants could be identified, with four seropositive participants in one school as the maximum. The seroprevalence ranged from 0 to 2.2 per individual school.

Of the few participants with a personal history of a SARS-CoV-2 infection, $4 / 5$ were seropositive, with the 


\begin{tabular}{|c|c|c|c|c|}
\hline & \multicolumn{2}{|c|}{ First study visit (May/June) } & \multicolumn{2}{|c|}{ Second study visit (September/October) } \\
\hline & Students & Teachers & Students & Teachers \\
\hline Participants & $1538(75.2 \%)$ & $507(24.8 \%)$ & $1334(75 \%)$ & $445(25 \%)$ \\
\hline Woman & $802(52 \%)$ & $357(70 \%)$ & $680(51 \%)$ & $313(70 \%)$ \\
\hline Household size & $4(3-5)$ & $2(2-4)$ & $4(3-5)$ & $2(2-4)$ \\
\hline $\begin{array}{l}\text { Regular social contacts outside the student's } \\
\text { household/classroom during the March } 2020 \\
\text { lockdown }\end{array}$ & $1230(80 \%)$ & & & \\
\hline Respiratory symptoms between study visits & & & $587(44 \%)$ & $71(16 \%)$ \\
\hline Febrile illness between study visits & & & $67(5 \%)$ & $4(0.9 \%)$ \\
\hline
\end{tabular}

Demographic and clinical characteristics at baseline and follow-up. Data are presented as numbers with percentages except for age, which is presented as median with IQR.

fifth showing only an equivocal test result in one of the assays. Of all participants with a household history of a SARS-CoV-2 infection, 23/24 were seronegative, with 22/24 showing negative results in all three assays and one showing an equivocal result in only one assay.

During the study period, laboratory-confirmed SARS-CoV-2 infections per 100000 inhabitants in Saxony increased from 139 to 245, and 7-day incidence rates ranged from $1 / 100000$ to 30/100 000 .

\section{DISCUSSION}

The findings from this unique study in older students and their teachers indicate that the prevalence of IgG antibodies against SARS-CoV-2 was very low after the first wave of the corona pandemic in Germany and during the reopening of the schools in May 2020 and remained low after summer holidays 2020. While this finding is consistent with local surveillance data ${ }^{12}$ that show a prevalence of PCR-confirmed cases of $0.8 \%$, it clearly indicates that schools did not develop into silent hotspots of SARS-CoV-2 transmission during the first wave of the pandemic and even more importantly after reopening of the schools in May 2020. Even more important is the fact that there was no increase in seropositivity and infections, respectively, in the 4 months between May after reopening and October after the summer holidays and the first weeks of back to school in the fall period. Therefore, herd immunity in the population of students and teachers appears not to contribute substantially to protection in a lowprevalence setting.

It has to be pointed out, however, that the infection rate in Saxony was constantly low during this time period. Nevertheless, the most relevant observation is that infection rates do not increase silently in schools when infection rates in the population are low. Of course, this does not preclude that with increasing infection rates in the population, infection rates in schools may also increase, which is an important reminder that the general population has to act prudently in order to keep schools open.

In fact, five of the 12 participants with antibodies against SARS-CoV-2 had a personal or household history of COVID-19, yielding a ratio of unidentified to identified cases of 1.4, which is much smaller than that previously assumed by some authors. ${ }^{13}$ We could not detect a single cluster of infections in the participating schools, even though at least three schools did have confirmed SARS-CoV-2 cases before the March 13 lockdown in Saxony. This is consistent with findings from the 2003 severe acute respiratory syndrome outbreak ${ }^{14}$ and calls the effectiveness of transmission control measures focused mainly on the student population into question. This is especially relevant since there are clearly described adverse effects of school closures, as loss of education, loss of social contacts and social control, nutritional problems in children who rely on school meals, increases in harm to child welfare in vulnerable populations and economic harm caused by loss to productivity due to parents being forced from work to childcare. ${ }^{16} 17$ Additionally, even with school closures in place, social contacts continue as informal childcare and non-school gatherings, ${ }^{18}$ thereby reducing the potential benefit of school closures further. Our data support this finding since an overwhelming majority of not less than $80 \%$ of the participating students in our study reported to have regular social contacts outside their household or classroom.

While close contact with patients with COVID-19-especially in the same household-has been shown to increase viral transmission, ${ }^{19}$ a review of household transmission studies found secondary attack rates of only $0.17^{20}$ with underage household members being less likely affected compared with adults. Our finding that only one out of 24 participants with a confirmed SARS-CoV-2 infection in the same household became indeed infected as measured by antibody production supports these findings as well as 
findings that children in general appear to be less susceptible to SARS-CoV-2 compared with adults. ${ }^{21}{ }^{22}$ In addition, these results support studies showing that certain quarantine and separation measures can effectively reduce the probability of viral transmission even in closecontact situations. ${ }^{23}$

The fact that we could not detect one additional seropositive participant in over 4 months is surprising even in a low-prevalence setting, given that the reported cases doubled in the same period of time in Saxony. One explanation might be the recently reported detection of SARS-CoV-2 spike-reactive CD4+ T cells in 35\% of SARS-CoV-2-unexposed healthy blood donors arguing for a certain level of T-cell cross-reactivity. Such reactions could arise from exposure to commonly encountered coronaviruses. With children being frequently exposed to common coronaviruses, it might be hypothesised that they are less susceptible to SARS-CoV-2 infection due to a background of T-cell cross-reactivity. ${ }^{24}$

Currently, no gold standard serological testing strategy for SARS-CoV-2 exists. Even though immunoassays yield better performance than rapid point-of-care tests ${ }^{19}$ and the targeted SARS-CoV-2 S protein and nucleoprotein show a similarity of less than $30 \%$ to endemic betacoronaviruses ${ }^{25}$ false-positive results are still a concern, especially in low-prevalence populations and when interpreting results on a personal rather than a population-based level. By using a combination of three different immunoassays and only regarding participants with at least two positive results as seropositive for SARS-CoV-2, we could exclude ten participants with a positive and six with an equivocal initial test by negative confirmatory testing. In our population, a positive predictive value (PPV) of $42.9 \%$ could be observed, which was near an expected PPV of $45.3 \%$ for a prevalence of $0.59 \%$ population and the given test characteristics (sensitivity, 97.6\%; specificity, 99.3\%). By using this approach, we could reliably identify patients with confirmed seropositivity against SARS-CoV-2 in a low-prevalence population.

There are several limitations to our study. We cannot provide information on eligible but non-participating students and teachers in the selected schools requiring additional caution when generalising these results. In addition, there is a relevant loss of participants in the follow-up sampling. While we do not have information why certain individuals dropped out, the fact that the second study visit took place before the beginning of the second wave (7-day incidence rates around 30/100 000) makes it unlikely that personal illness or widespread quarantine measures were responsible for this drop in participation

\section{CONCLUSION}

As for now, students and teacher do not seem to play a substantial role in driving the SARS-CoV-2 pandemic in Germany when observing the period after reopening of schools in May as well as after summer holidays until early autumn 2020 before facing the second pandemic wave. Transmission in families appears to occur very infrequently, and the number of unreported cases obviously is low in this age group. For serological testing, a combination of different immunoassays seems to be effective to increase the number of true positive test results.

Contributors $\mathrm{JA}, \mathrm{RB}$ and $\mathrm{AHD}$ designed the study and wrote the protocol. JA, MU and CK collected samples. AHD and CL performed serological testing. JA, MU, CK and RB analysed the data. JA and CK wrote the manuscript. MU, AHD, CL and RB reviewed the manuscript.

Funding This study was supported by a grant from the state of Saxony. Grant name: CoviDD19.

Disclaimer The funder of the study had no role in the study design, data collection, data analysis, data interpretation or writing of the report. The corresponding authors had full access to all the data in the study and had final responsibility for the decision to submit for publication.

Competing interests None declared.

Patient consent for publication Not required.

Ethics approval The SchoolCoviDD19 study was approved by the ethics committee of the Technische Universität Dresden (B0-EK-156042020) and was registered on 23 July 2020 and assigned the clinical trial registration number DRKS00022455. All participants and their legal guardians-when applicableprovided informed consent.

Provenance and peer review Not commissioned; externally peer reviewed.

Data availability statement Data are available on reasonable request: jakob. armann@uniklinikum-dresden.de.

Supplemental material This content has been supplied by the author(s). It has not been vetted by BMJ Publishing Group Limited (BMJ) and may not have been peer-reviewed. Any opinions or recommendations discussed are solely those of the author(s) and are not endorsed by BMJ. BMJ disclaims all liability and responsibility arising from any reliance placed on the content. Where the content includes any translated material, BMJ does not warrant the accuracy and reliability of the translations (including but not limited to local regulations, clinical guidelines, terminology, drug names and drug dosages), and is not responsible for any error and/or omissions arising from translation and adaptation or otherwise.

Open access This is an open access article distributed in accordance with the Creative Commons Attribution Non Commercial (CC BY-NC 4.0) license, which permits others to distribute, remix, adapt, build upon this work non-commercially, and license their derivative works on different terms, provided the original work is properly cited, appropriate credit is given, any changes made indicated, and the use is non-commercial. See: http://creativecommons.org/licenses/by-nc/4.0/.

ORCID iD

Jakob Armann http://orcid.org/0000-0002-5418-6416

\section{REFERENCES}

1 Zhu N, Zhang D, Wang W, et al. A novel coronavirus from patients with pneumonia in China, 2019. N Engl J Med 2020;382:727-33.

2 UNESCO. Education: from disruption to recovery, 2020. Available: https://en.unesco.org/covid19/educationresponse

3 Viner RM, Russell SJ, Croker H, et al. School closure and management practices during coronavirus outbreaks including COVID-19: a rapid systematic review. Lancet Child Adolesc Health 2020;4:397-404.

4 Cowling BJ, Ali ST, Ng TWY, et al. Impact assessment of nonpharmaceutical interventions against coronavirus disease 2019 and influenza in Hong Kong: an observational study. Lancet Public Health 2020;5:e279-88.

5 CDC COVID-19 Response Team. Coronavirus Disease 2019 in Children - United States, February 12-April 2, 2020. MMWR Morb Mortal Wkly Rep 2020;69:422-6.

6 COVID-19 National Incident Room Surveillance Team. COVID-19, Australia: epidemiology report 11 (reporting week to 23:59 AEST 12 April 2020). Commun Dis Intell 2018;2020:44.

7 Armann JP, Diffloth N, Simon A, et al. Hospital admission in children and adolescents with COVID-19. Dtsch Arztebl Int 2020;117:373-4. 
8 Lai C-C, Wang J-H, Hsueh P-R. Population-Based seroprevalence surveys of anti-SARS-CoV-2 antibody: an up-to-date review. Int J Infect Dis 2020;101:314-22.

9 Macartney K, Quinn HE, Pillsbury AJ, et al. Transmission of SARSCoV-2 in Australian educational settings: a prospective cohort study. Lancet Child Adolesc Health 2020;4:807-16.

10 Ismail SA, Saliba V, Lopez Bernal J, et al. SARS-CoV-2 infection and transmission in educational settings: a prospective, cross-sectional analysis of infection clusters and outbreaks in England. Lancet Infect Dis 2021;21:344-353.

11 Brandal LT, Ofitserova TS, Meijerink H, et al. Minimal transmission of SARS-CoV-2 from paediatric COVID-19 cases in primary schools, Norway, August to November 2020. Euro Surveill 2021;26.

12 Zusammenhalt, Sächsisches Staatsministerium für Soziales und Gesellschaftlichen. Infektionsfälle in Sachsen - sachsen.de, 2020. Available: https://www.coronavirus.sachsen.de/infektionsfaelle-insachsen-4151.html

13 Li R, Pei S, Chen B, et al. Substantial undocumented infection facilitates the rapid dissemination of novel coronavirus (SARSCoV-2). Science 2020;368:489-93.

14 Liao C-M, Chang C-F, Liang H-M. A probabilistic transmission dynamic model to assess indoor airborne infection risks. Risk Anal 2005;25:1097-107.

15 Wong GW, Fok TF. Severe acute respiratory syndrome (SARS) in children. Pediatr Pulmonol Suppl 2004;26:69-71.

16 Jackson C, Mangtani P, Hawker J, et al. The effects of schoo closures on influenza outbreaks and pandemics: systematic review of simulation studies. PLoS One 2014;9:e97297.
17 Bin Nafisah S, Alamery AH, Al Nafesa A, et al. School closure during novel influenza: a systematic review. J Infect Public Health 2018;11:657-61.

18 Rashid H, Ridda I, King C, et al. Evidence compendium and advice on social distancing and other related measures for response to an influenza pandemic. Paediatr Respir Rev 2015;16:119-26.

19 Pollán M, Pérez-Gómez B, Pastor-Barriuso R, et al. Prevalence of SARS-CoV-2 in Spain (ENE-COVID): a nationwide, population-based seroepidemiological study. Lancet 2020;396:535-44.

20 Madewell ZJ, Yang Y, Longini IM, et al. Household transmission of SARS-CoV-2: a systematic review and meta-analysis. JAMA Netw Open 2020;3:e2031756.

21 Koh WC, Naing L, Chaw L, et al. What do we know about SARSCoV-2 transmission? A systematic review and meta-analysis of the secondary attack rate and associated risk factors. PLoS One 2020;15:e0240205.

22 Viner RM, Mytton OT, Bonell C, et al. Susceptibility to SARSCoV-2 infection among children and adolescents compared with adults: a systematic review and meta-analysis. JAMA Pediatr 2021;175:143-56.

23 Galow LV, Haag L, Kahre E, et al. Lower Household Transmission Rates of SARS-CoV-2 from Children Compared to Adults - Results from the FamilyCoviDD19-Study. SSRN Journal 2021.

24 Braun J, Loyal L, Frentsch M, et al. SARS-CoV-2-reactive T cells in healthy donors and patients with COVID-19. Nature 2020;587:270-4.

25 Theel ES, Slev P, Wheeler S, et al. The role of antibody testing for SARS-CoV-2: is there one? J Clin Microbiol 2020;58. 